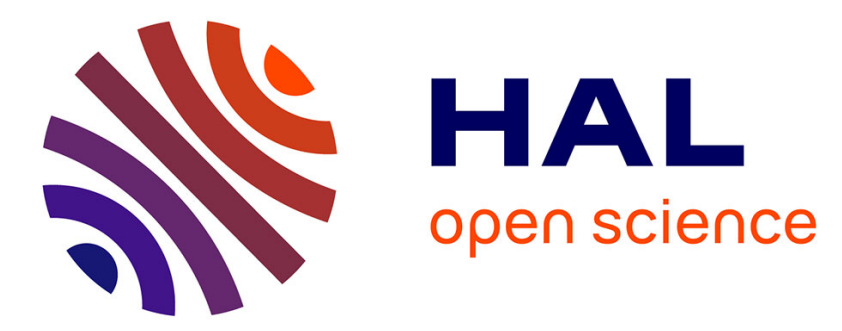

\title{
Multi-scales Characterization of the Early-age Creep of Concrete
}

\author{
M. Farah, F. Grondin, M. Matallah, A. Loukili, J. Saliba
}

\section{To cite this version:}

M. Farah, F. Grondin, M. Matallah, A. Loukili, J. Saliba. Multi-scales Characterization of the Earlyage Creep of Concrete. Ninth International Conference on Creep, Shrinkage, and Durability Mechanics (CONCREEP-9), Sep 2013, Cambridge, United Kingdom. pp.211-218, 10.1061/9780784413111.024 . hal-02444546

\section{HAL Id: hal-02444546 \\ https://hal.science/hal-02444546}

Submitted on 21 Jan 2020

HAL is a multi-disciplinary open access archive for the deposit and dissemination of scientific research documents, whether they are published or not. The documents may come from teaching and research institutions in France or abroad, or from public or private research centers.
L'archive ouverte pluridisciplinaire HAL, est destinée au dépôt et à la diffusion de documents scientifiques de niveau recherche, publiés ou non, émanant des établissements d'enseignement et de recherche français ou étrangers, des laboratoires publics ou privés. 


\title{
Multi-scales characterization of the early-age creep of concrete
}

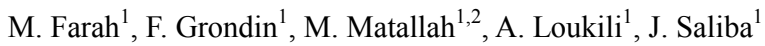 \\ ${ }^{1}$ Institut de Recherche en Génie Civil et Mécanique (GeM), UMR-CNRS 6183, Ecole \\ Centrale de Nantes, 1 rue de la Noé, F-44321 Nantes; email: \{mounia.farah, \\ frederic.grondin, mohammed.matallah, ahmed.loukili, jacqueline.saliba\}@ec-nantes.fr. \\ ${ }^{2}$ RiSAM, Université de Tlemcen BP 230 Tlemcen, Algérie, e-mail: matallah@mail.univ- \\ tlemcen.dz
}

\begin{abstract}
Concrete is a heterogeneous material that develops delayed strains under a constant load. These deformations are related to micromechanisms which occur in its microstructure. To model this behaviour a new numerical multi-scales method is suggested. Based on a method for the calculation of the effective response for a nonaging material, an extension to aging materials has been developed. This method operates directly in space-time and avoids the difficulties of Laplace Carson transform inversion. The delayed strains are calculated in a representative elementary volume thanks to classical finite elements method which allows determining the components of the creep compliance tensor. First of all, calculations have been performed for an uniaxial loading to model the creep strain at different scales in order to give the viscoelastic property of calcium silicate hydrates. Then, the evolution of the microstructure with age has been considered to model the creep at early-ages of concrete.
\end{abstract}

\section{Introduction}

The prediction of creep of concrete is a major challenge for the civil engineering structures. In fact, concrete is a heterogeneous visco-elastic material that develops delayed deformations. According to several studies, the visco-elastic behaviour is strongly linked to calcium silicate hydrates (C-S-H). Because of their solid sheets composition separated by adsorbed water, they can be deformed due to the movement of water causing the sliding of the solid layers. During the solidification of the cement paste at early-ages, a maximum deformation is observed (Bazant, 1988). These important deformations restrained by the presence of aggregates cause microcracks in the paste witch can be prejudicial to a good performance of the structure (Saliba et al., 2012).

The study of the cement paste morphology is of particular interest to evaluate the macroscopic behaviour of concrete (Sanahuja, 2009). For this reason, homogenization techniques seem to be the best method to calculate the effective behaviour from the description of the local behaviour. Indeed, for a visco-elastic heterogeneous material, the 
correspondence principle between elasticity and linear visco-elasticity through the Carson-Laplace transform is used. This allows using classical homogenization schemes (Mori-Tanaka, self-consistent scheme, etc.) directly in the transformed space (Christensen, 1969) and (Hashin, 1962). Effective visco-elastic properties are derived by inverting the Laplace-Carson transform. Most of these techniques are limited to nonaging materials and the extension to aging materials is rarely dealt (Briffaut et al., 2011) due to difficulties of inverting the Laplace-Carson transform. Within this framework, the aim of this work is to introduce an original multi-scales method for creep of concrete at early-ages taking into account the evolution of the microstructure (Grondin et al., 2010). This method operates directly in time domain (Tran et al., 2011) and avoids difficulties of inverting the Laplace-Carson transform.

To model the cementitious materials at different scales it is possible to represent at each scale the material by a matrix and inclusions of different sizes. To simulate the creep, a constant load is applied to the volume and local stresses and strains fields are calculated. The relation between the average of stresses and strains allows deducing the effective tensor of creep compliance. This work is divided into two parts: the determination of creep properties of the concrete constituents and the evolution of creep in terms of the age of concrete. Here, the first part highlights the evaluation of creep compliance of the C-S-H which could be considered intrinsic in the second part. For this, their visco-elastic parameters are estimated by inverse approach starting from an experimental comparison made on concrete.

\section{Multi-scales model of creep for a non-aging material}

The volume $\mathrm{V}$ of the studied material is formed by two phases: a matrix volume $\mathrm{V}_{\mathrm{m}}$ and inclusions volume $\mathrm{V}_{\mathrm{i}}$. Locally, only the matrix is considered visco-elastic and its compliance is defined for a model of Kelvin-Voigt with three chains (Figure 1), with E the elastic modulus, $\mathrm{k}_{\mathrm{i}}$ the stiffness and $\tau_{i}$ the characteristic time:

$$
J(t)=\frac{1}{E}+\sum_{i=1}^{i=3} \frac{1}{k_{i}}\left(1-e^{\frac{-t}{\tau_{i}}}\right)
$$

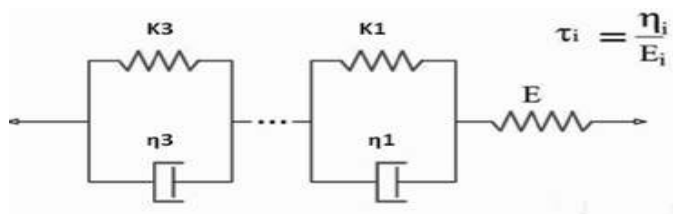

Figure 1. Generalized bounded Kelvin-Voigt model.

A constant load $\mathrm{F}$ is applied on one of the surface boundary $\Gamma_{1}$ of $\mathrm{V}$ according to the unit normal vector $\underline{n}$. This load implies local displacements fields $\underline{u}(\underline{y})$, local strain 
fields $\underline{\underline{\varepsilon}}(\underline{y})$ and local stress fields $\underline{\underline{\sigma}}(\underline{y})$ in each point $\underline{y}$ of $\mathrm{V}$. The non-linear viscoelastic problem is written as follows:

$$
\begin{array}{ll}
\underline{\operatorname{div}} \underline{\underline{\sigma}}(\underline{y})=\underline{0} & \underline{y} \in V \\
\left.\underline{\underline{\sigma}} \underline{y} \underline{y})=C(\underline{\underline{\varepsilon}}(\underline{y}), \underline{y}):(\underline{\underline{\varepsilon}} \underline{y})-\underline{\underline{\varepsilon}}^{v}(\underline{y})\right) & \underline{y} \in V \\
\underline{\underline{\varepsilon}}(\underline{y})=\frac{1}{2}\left(\underline{\underline{\nabla}} \underline{u}(\underline{y})+{ }^{t} \underline{\underline{\nabla}} \underline{u}(\underline{y})\right) & \underline{y} \in V \\
\underline{F}=\underline{\underline{\sigma}} \underline{n} & \underline{y} \in \Gamma_{1} \\
\underline{u}=0 & \underline{y} \in \Gamma_{2}
\end{array}
$$

Where $C(\underline{\underline{\varepsilon}}(\underline{y}), \underline{y})$ is the secant stiffness tensor depending on the local strains and damage (Saliba et al., 2013), $\underline{\varepsilon}^{v}(\underline{y})$ the local visco-elastic strain fields (for inclusions $\underline{\varepsilon}^{v}(y)=0$ ) and $\Gamma_{2}$ the boundary of $\mathrm{V}$ on which macroscopic displacements conditions are applied. The chosen damage model is the isotropic model developed by Fichant (Fichant et al., 1997) based on the microplan theory.

The volume is modeled by finite elements. The resolution of the local problem gives a relation between the average stresses $\langle\sigma\rangle_{\mathrm{V}}$ and the average strains $\langle\varepsilon\rangle_{\mathrm{V}}$ linked by the effective creep tensor $J^{\text {hom }}$ :

$$
\langle\boldsymbol{\varepsilon}\rangle_{V}=\boldsymbol{J}^{\text {hom }}:\langle\boldsymbol{\sigma}\rangle_{V}
$$

To determine the visco-elastic properties of the concrete components, an inverse approach is used. At each step the visco-elastic coefficients of the matrix are calibrated to adjust the result of the material volume. At the first step, concrete is represented by a mortar matrix and the real aggregate size distribution is generated in the volume. The visco-elastic coefficients of mortar are adjusted from experimental results on concrete. These coefficients allow defining the creep compliance of mortar (equation [1]). At the second step, mortar is represented by a cement paste matrix and the real sand grains size distribution. The inverse approach is used to characterize the visco-elastic coefficients of the cement paste. Then, at the lower scale, an assumption is made on the visco-elasticity of the cement paste to be strictly dependent on that of the C-S-H. Thus, the cement paste is represented as a heterogeneous medium formed by a matrix of $\mathrm{C}-\mathrm{S}-\mathrm{H}$ and inclusions composed by the other hydrated phases and residual clinkers $(\mathrm{CH}$, Ettringite, gypsum, $\mathrm{C}_{3} \mathrm{AH}_{6}, \mathrm{FH}_{3}, \mathrm{C}_{3} \mathrm{~S}, \mathrm{C}_{2} \mathrm{~S}, \mathrm{C}_{3} \mathrm{~A}, \mathrm{C}_{4} \mathrm{AF}$ ). In this case, only one type of particle is considered with a unique size and their elastic characteristics are derived from the average of the elastic characteristics of the different hydrates and clinkers. The visco-elastic parameters of C-S-H are then calibrated to find the creep compliance $\mathrm{J}^{\text {hom }}$ defined in the previous 
step for the cement paste. The volume fraction of each component of the cement paste is determined by a hydration model (Grondin et al., 2010).

Volumes are generated by using a digital concrete model developed by (Mounajed, 2002). Geometries are showed in figure 2.

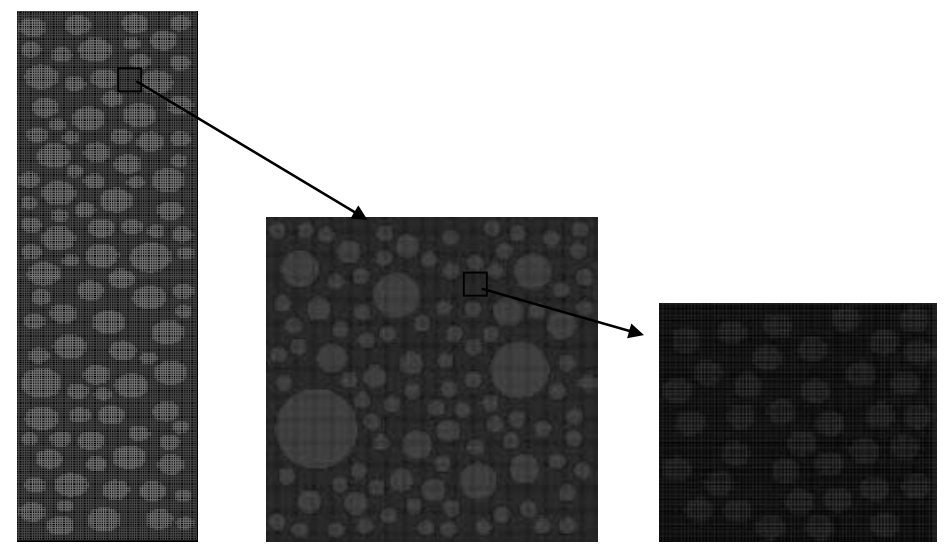

Figure 2. Geometry descriptions of concrete, mortar and cement paste.

\section{Results for a non aging material}

Direct tensile tests have been realized on cylindrical specimens of concrete (Saliba et al., 2013). The experimental results achieved for a load of $70 \%$ of the tensile strength have shown with the help of acoustic emission technique that the damage did not develop during creep, but only during the instantaneous loading. This allows characterizing the creep compliance regardless of the damage. The composition of concrete is given in detail in (Saliba et al., 2012). The visco-elastic coefficients of mortar are calibrated to well reproduce the evolution of the creep compliance of concrete for a load of $70 \%$ of its tensile strength $(2.5 \mathrm{MPa})$ (Figure 3 ).

According to these results, the visco-elastic parameters of cement paste are then calibrated for calculations made on the mortar volume (Figure 4). Finally, for the cement paste volume the volume fraction of $\mathrm{C}-\mathrm{S}-\mathrm{H}$ is assessed equal to $70 \%$ (including pores), corresponding to a hydration degree of 0.78 . The inclusions have a unique size equal to $30 \mu \mathrm{m}$ with a volume fraction of $30 \%$. The visco-elastic matrix coefficients are calibrated to obtain the creep compliance of the cement paste determined in the previous step (Figure 5). The material parameters obtained are presented in Table 2 (ft: tensile strength, $v 0$ : Poisson coefficient; $\mathrm{G}_{\mathrm{f}}$ : fracture energy). 


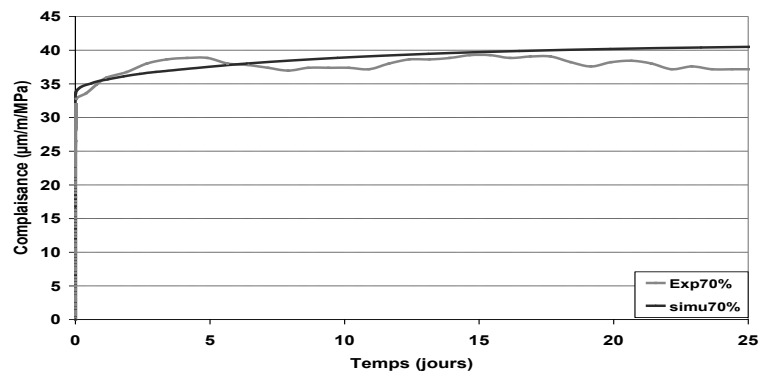

Figure 3. Comparison between the measured concrete compliance and that obtained with the calibrated coefficients of mortar.

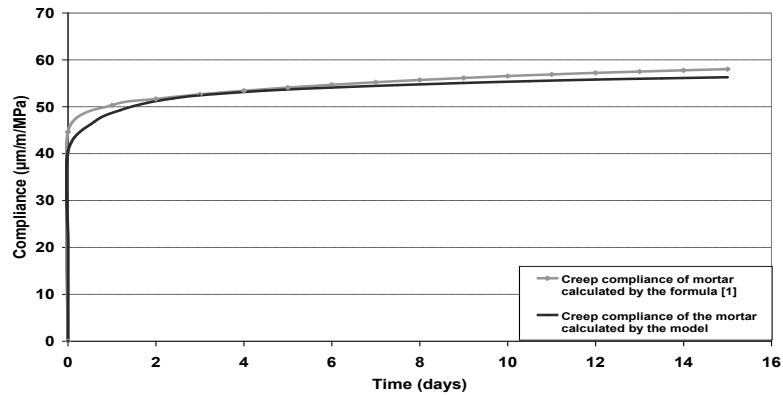

Figure 4. Comparison between the creep compliance of mortar obtained at the previous step and that obtained with the calibrated coefficients of the cement paste.

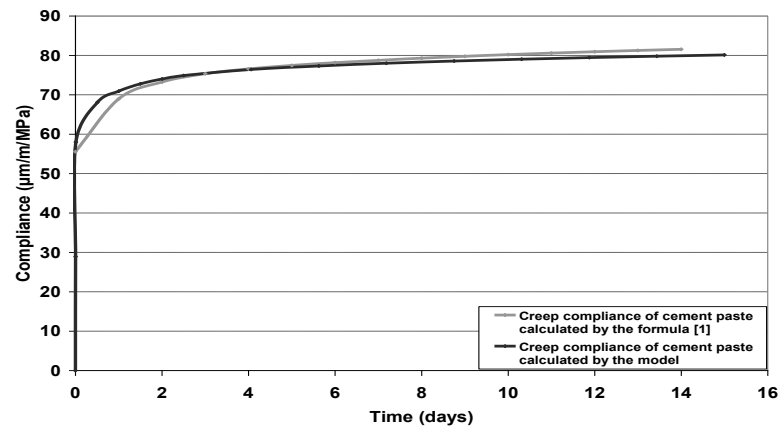

Figure 5. Comparison between the creep compliance of the cement paste obtained at the previous step and that obtained with the calibrated coefficients of $\mathrm{C}-\mathrm{S}-\mathrm{H}$. 
Table 1. Model parameters for mortar and aggregates

\begin{tabular}{|lccccccc|}
\hline & $\mathrm{E}(\mathrm{GPa})$ & $\mathrm{v} 0$ & $\mathrm{ft}(\mathrm{MPa})$ & $\mathrm{Gf}(\mathrm{J} / \mathrm{m} 2)$ & $\mathrm{k}_{\mathrm{fp}}^{\mathrm{I}}(\mathrm{GPa})$ & $\mathrm{k}_{\mathrm{fp}}^{2}(\mathrm{GPa})$ & $\mathrm{k}_{\mathrm{fp}}^{3}(\mathrm{GPa})$ \\
\hline Mortar & 22.4 & 0.24 & 2.0 & 45 & 776.7 & 472 & 98.1 \\
\hline Aggregates & 60 & 0.24 & 6 & 80 & - & - & - \\
\hline Cement Paste & 18 & 0.2 & 1.9 & 15 & 300 & 100 & 90 \\
\hline Sand grains & 80 & 0.24 & 4 & 40 & - & - & - \\
\hline C-S-H & 12 & 0.13 & 1.6 & 0.5 & 150 & 50 & 65 \\
\hline Inclusions in CP & 45 & 0.3 & 3 & 5 & - & - & - \\
\hline
\end{tabular}

\section{Suggestions for aging material}

The volume fractions of the constituents of the cement paste change with the evolution of the degree of hydration. Thus, the visco-elastic parameters are dependent on the pores volume fraction. An analytical method (Ricaud and Masson, 2009) is used to find the intrinsic value $\left(\mathrm{k}_{\text {int }}^{\mathrm{i}}\right)$ of C-S-H, independent of the pores volume $(\mathrm{p})$ :

$$
k_{\mathrm{int}}^{i}=k_{f p}^{i} \frac{3 \cdot A\left(f_{p}\right)}{4} \quad \text { with } A\left(f_{p}\right)=\frac{f_{p}}{1-f_{p}}
$$

$\mathrm{k}_{\text {int }}^{\mathrm{i}}$ is obtained for $\mathrm{C}-\mathrm{S}-\mathrm{H}$ for ages after $48 \mathrm{~h}$ of hydration. Then, knowing the pore volume fraction at different ages, calculated with the hydration model presented in (Grondin et al., 2010), $\mathrm{k}_{\mathrm{fp}}^{\mathrm{i}}$ at different ages is calculated (table 7). The creep compliance of cement paste is calculated on the REV and the figure 7 shows that it is more important at early ages. The evolution of the effective creep parameters of cement paste and mortar are calculated on REV (table 7). As well as the compliance of the cement paste the creep compliance of mortar (Figure 6) and concrete are more important at early ages (Figure7).

Table 2. Evolution of the C-S-H parameters

\begin{tabular}{|l|cccccc|}
\hline & Age & $\mathrm{E}(\mathrm{GPa})$ & $\mathrm{k}_{\mathrm{fp}}^{\mathrm{l}}(\mathrm{GPa})$ & $\mathrm{k}_{\mathrm{fp}}^{2}(\mathrm{GPa})$ & $\mathrm{k}_{\mathrm{fp}}^{3}(\mathrm{GPa})$ & $\mathrm{p}(\%)$ \\
\hline \multirow{3}{*}{ C-S-H (excluding pores) } & $16 \mathrm{~h}$ & 9.5 & 66.46 & 22.15 & 28.8 & 63 \\
\cline { 2 - 7 } & $24 \mathrm{~h}$ & 10.5 & 142.74 & 47.58 & 61.84 & 44.2 \\
\cline { 2 - 7 } & $>48 \mathrm{~h}$ & 12 & 148.24 & 49.41 & 64.24 & 43.29 \\
\hline \multirow{3}{*}{ Cement paste } & $16 \mathrm{~h}$ & 13.12 & 170.43 & 56.81 & 51.13 & 43 \\
\cline { 2 - 7 } & $24 \mathrm{~h}$ & 15.85 & 286.18 & 95.39 & 85.85 & 31 \\
\cline { 2 - 7 } & $>48 \mathrm{~h}$ & 16.7 & 300 & 100 & 90 & 30 \\
\hline \multirow{3}{*}{ Mortar } & $16 \mathrm{~h}$ & 17 & 483.91 & 294.07 & 61.12 & 28.38 \\
\cline { 2 - 7 } & $24 \mathrm{~h}$ & 21 & 745.46 & 453.02 & 94.15 & 20.46 \\
\cline { 2 - 7 } & $>48 \mathrm{~h}$ & 24 & 776.7 & 472 & 98.1 & 19.8 \\
\hline
\end{tabular}




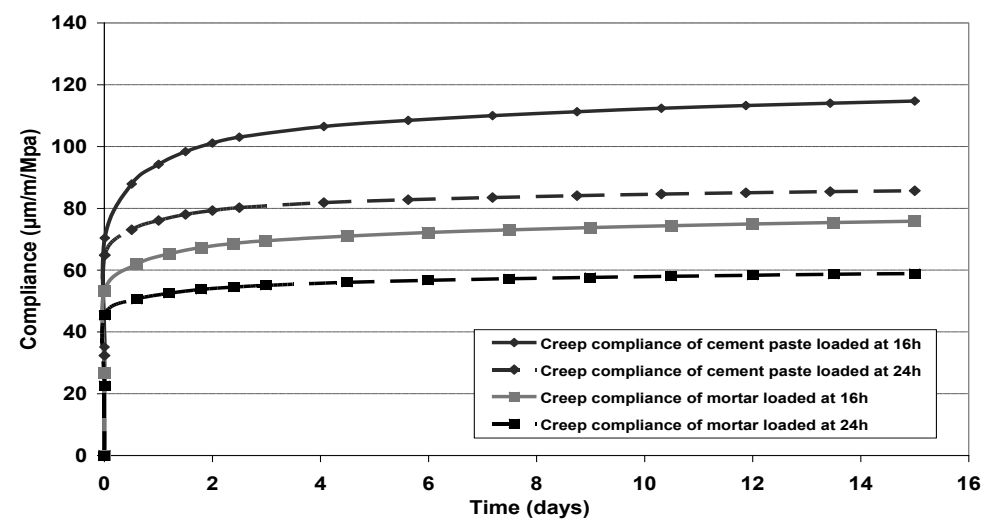

Figure 6. Influence of age on the creep compliance of cement paste and mortar.

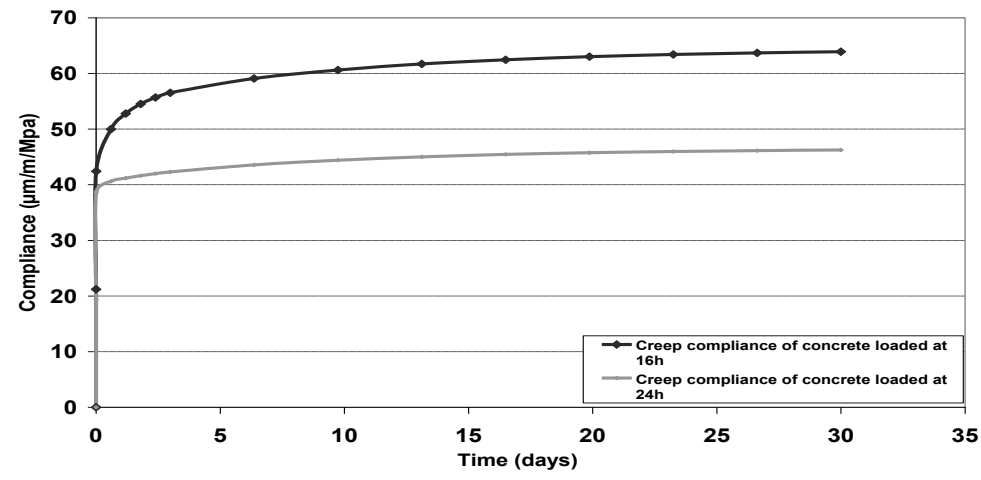

Figure 7. Influence of age on the creep compliance of concrete.

\section{Conclusion and perspectives}

The proposed multi-scales model allows taking into account the different phases of concrete. The major goal was first to determine the visco-elastic parameters which could be considered intrinsic. The objective is the checking of the solidification theory (Bazant, 1988) considering that only the volume fraction of cement paste components determines the viscosity as a function of the age of concrete. Another point will be dealt on consideration of the presence of the interface transition zone between aggregates and the matrix. Also, experimental tests will be made to compare numerical results. 


\section{References}

Bazant Z.P., Prasannan S. (1988). "Solidification theory for aging creep", Cement and Concrete Research, 18, 923-932.

Briffaut M., Benboudjema F., Torrenti J.M., Nahas G. (2011). "Numerical analysis of the thermal active restrained shrinkage ring test to study the early age behavior of massive concrete structures", Engineering Structures, 33, 1390-1401.

Christensen R.M. (1969). "Viscoelastic properties of heterogeneous media", Journal of Mechanics and Physcis of Solids, 17, 23-41.

Fichant, S., Pijaudier-Cabot, G., La Borderie, C. (1997). "Continuum damage modeling: approximation of crack induced anisotropy", Mechanical Research Communications, 24 (2), 109-114.

Grondin F., Dumontet H., Ben Hamida A., Mounajed G., Boussa H. (2007). 'Multi-scales modelling for the behaviour of damaged concrete', Cement and Concrete Research, 37 (10), 1453-1462.

Grondin F., Bouasker M., Mounanga P., Khelidj A., Perronnet A. (2010). "Physicochemical deformations of solidifying cementitious systems: multiscale modeling", Materials and Structures, 43 (1), 151-165.

Hashin Z. (1962). "The elastic moduli of heterogeneous materials", Journal of Applied Mechanics, 29, 143-150.

Mounajed G. (2002). Exploitation du nouveau modèle Béton Numérique dans Symphonie : Concept, homogénéisation du comportement thermomécanique des BHP et simulation de l'endommagement thermique, Cahiers du CSTB n ${ }^{\circ} 3421$, septembre.

Ricaud J.M., Masson R. (2009). "Effective properties of linear viscoelastic heterogeneous media: Internal variables formulation and extension to ageing behaviours", International Journal of Solids and Structures, 46, 1599-1606.

Saliba J., Loukili A., Grondin F., Regoin J;-P. (2012). "Influence of basic creep on cracking of concrete shown by the Acoustic Emission technique", Materials and Structures, 45, 1389-1401.

Saliba J., Grondin F., Matallah M., Loukili A., Boussa H. (2013). "Relevance of a mesoscopic modelling for the coupling between creep and damage in concrete", Mechanics of Time-Dependent Materials, DOI 10.1007/s11043-012-9199-4.

Sanahuja J., Dormieux L., Le pape Y.,Toulemonde C. (2009). "Modélisation micromacro du fluage propre du béton », 19éme Congrès Français de Mécanique, Marseille, 24- 28 août.

Tran A.B., Yvonnet J., He Q.-C., Toulemonde C., Sanahuja J. (2011). «A simple computational homogenization method for structures made of linear heterogeneous viscoelastic materials", Computer Methods in Applied Mechanical Engineering, 200, 2956-2970. 